\title{
Use of probiotics in the treatment of severe acute pancreatitis: a systematic review and meta-analysis of randomized controlled trials
}

\author{
Shanmiao Gou, Zhiyong Yang, Tao Liu, Heshui Wu and Chunyou Wang*
}

\begin{abstract}
Introduction: Necrotic tissue infection can worsen the prognosis of severe acute pancreatitis (SAP), and probiotics have been shown to be beneficial in reducing the infection rate in animal experiments and primary clinical trials. However, the results of multicenter randomized clinical trials have been contradictory. Our aim in this study was to systematically review and quantitatively analyze all randomized controlled trials with regard to important outcomes in patients with predicted SAP who received probiotics.
\end{abstract}

Methods: A systematic literature search of the PubMed, Embase and Cochrane Library databases was conducted using specific search terms. Eligible studies were randomized controlled trials that compared the effects of probiotic with placebo treatment in patients with predicted SAP. Mean difference (MD), risk ratio (RR) and 95\% confidence interval $(95 \% \mathrm{Cl})$ were calculated using the Mantel-Haenszel fixed- and random-effects models. A meta-analysis on the use of probiotics in the treatment of critically ill patients was also performed to serve as a reference.

Results: In this study, 6 trials comprising an aggregate total of 536 patients were analyzed. Significant heterogeneities were observed in the type, dose, treatment duration and clinical effects of probiotics in these trials. Systematic analysis showed that probiotics did not significantly affect the pancreatic infection rate $(\mathrm{RR}=1.19,95 \% \mathrm{Cl}=0.74$ to 1.93 ; $P=0.47$ ), total infections $(\mathrm{RR}=1.09,95 \% \mathrm{Cl}=0.80$ to $1.48 ; P=0.57)$, operation rate $(\mathrm{RR}=1.42,95 \% \mathrm{Cl}=0.43$ to 3.47 ; $P=0.71)$, length of hospital stay $(\mathrm{MD}=2.45,95 \% \mathrm{Cl}=-2.71$ to $7.60 ; P=0.35)$ or mortality $(\mathrm{RR}=0.72,95 \% \mathrm{Cl}=0.42$ to $1.45 ; P=0.25)$.

Conclusions: Probiotics showed neither beneficial nor adverse effects on the clinical outcomes of patients with predicted SAP. However, significant heterogeneity was noted between the trials reviewed with regard to the type, dose and treatment duration of probiotics, which may have contributed to the heterogeneity of the clinical outcomes. The current data are not sufficient to draw a conclusion regarding the effects of probiotics on patients with predicted SAP. Carefully designed clinical trials are needed to validate the effects of particular probiotics given at specific dosages and for specific treatment durations.

\section{Introduction}

Acute pancreatitis (AP) is a common disease that affects about 270,000 people annually in the United States, and its incidence has been increasing by $5 \%$ every year in the United States and Europe [1,2]. Severe acute pancreatitis (SAP) accounts for $10 \%$ to $20 \%$ of AP cases and has unacceptably high morbidity and mortality rates [3,4]. Necrotic tissue infection is one of the principal causes of

\footnotetext{
*Correspondence: chunyouwang52@126.com

Department of General Surgery, Pancreatic Disease Institute, Union Hospital, Tongji Medical College, Huazhong University of Science and Technology, 1277 Jiefang Avenue, Wuhan, Province Hubei 430022, China
}

complications and death in SAP patients. It is believed that intestinal barrier dysfunction and subsequent bacterial translocation from the intestinal tract to the bloodstream and necrotic tissues play a critical role in the infection of necrotic tissues [5-7]. Evidence derived from animal studies suggests that probiotics could stabilize the intestinal barrier and thus minimize bacterial translocation and prevent infection in AP [8-11]. Moreover, clinical trials have documented the benefits of probiotics in some critically ill patients [12-18]. The results of several studies indicate that probiotics can enhance intestinal barrier function, stimulate host cell production of antimicrobial peptides 
and produce antimicrobial factors, so probiotics could potentially be effective in the treatment of SAP [19-22]. Clinical trials have been conducted on the use of probiotics in AP patients at risk of developing SAP. However, disparate results were obtained from the trials; therefore, there is still no consensus about the use of probiotics in SAP [23-28], and their use is rarely recommended in clinical practice guidelines [2,29-38].

The results of the PROPATRIA trial (probiotic prophylaxis in patients with predicted severe acute pancreatitis), published in 2008 (a multicenter randomized controlled trial (RCT) dominated by the Dutch Acute Pancreatitis Study Group), showed that probiotics had harmful effects [23], which deterred the initiation of other trials on probiotics. In recent years, however, two other RCTs have been completed, with no negative consequences were in patients treated with probiotics [24,28]. We therefore consider that the results of the PROPATRIA trial are questionable and that further meta-analyses of the more recent RCTs is required. To this end, we performed this meta-analysis on six select RCTs in order to determine the effects of probiotics on the rate of pancreatic and total infection, operation rate, length of hospital stay and mortality. In addition, we tried to determine the reason for the heterogeneous results across the different trials.

\section{Methods}

\section{Systematic literature search}

A systematic literature search was performed in the PubMed, Embase and Cochrane Library databases. The search was restricted to human evidence published since 1992, which was the year in which the term severe acute pancreatitis was approved at the Atlanta symposium. The MeSH headings pancreatitis, Lactobacillus, prebiotics, synbiotics and probiotics were used, but the language was not restricted to English only. Articles were compiled into a database, and duplicates were removed. The abstracts were then screened for relevance. In the case of multiple articles published by the same study group for the same study period, only the most recent paper was selected. Subsequently, full-text papers of the selected studies published in English were screened for eligibility. If the study was published in another language, we contacted the corresponding author to check whether it had been translated into English. The translated studies were included, and nontranslated studies were eliminated. A systematic literature search for probiotic use in critical illness was also performed. An additional Microsoft Word file describing this search in more detail is available in Additional file 1. No participant consent were needed for this review, as it evaluated published studies without individually identifiable patient information.

\section{Inclusion and exclusion criteria}

We included all human RCTs in which the effects of probiotics in SAP patients were investigated. We excluded (1) trials that included patient cohorts with mild AP and in which the SAP results were not reported separately and (2) studies that included cohorts for which the essential outcomes were not reported. The search and inclusion or exclusion of articles were carried out by two authors (SG and TL). In cases of uncertainty or disagreement, a third author was consulted (CW).

\section{Data extraction}

From among the included studies, the following variables were extracted (if available): definition of predicted SAP, sample size, types of probiotics used and duration of use, intervention in the control group and clinical outcomes. The internal validity was determined using the Jadad score [39] and six quality criteria of the Cochrane Collaboration: random sequence generation, allocation concealment, blinding of participants and personnel, blinding of outcome assessment, incomplete outcome data and selective data reporting. Any publication bias was not evaluated.

\section{Statistical analysis}

All pooled data were analyzed using Review Manager (RevMan) version 5.2.6 software (Cochrane Informatics and Knowledge Management Department). Risk ratio (RR) with 95\% confidence interval (CI) was used for dichotomous outcomes, and mean difference (MD) was used for continuous outcomes. The $x^{2}$ test was used to assess heterogeneity between trials, and $I^{2}$ values were used to assess the extent of inconsistency. The Mantel-Haenszel random-effects model and fixed-effects model were used to analyze data with and without significant heterogeneity, respectively. Two-sided $P$-values $<0.05$ were considered to indicate statistical significance.

\section{Results}

\section{Included studies}

The results of the literature search are depicted in Figure 1. An initial search of the databases yielded a total of 259 articles. After screening titles and abstracts for relevance, 12 articles were assessed further for eligibility. Of the twelve articles, six were excluded: one was a retrospective study, three articles reported results of the same study, one article did not report the outcomes of mixed cohorts with severe and mild acute pancreatitis separately and, in one article, the experimental patients received probioticcontaining enteral nutrition (EN) and control patients received parenteral nutrition (PN) but not probiotic-free EN. Thus, six RCTs were ultimately included in our present systematic review [23-28]. The blinding, randomization, random sequence generation, withdrawals and dropouts, and allocation concealment for all the trials are listed in 


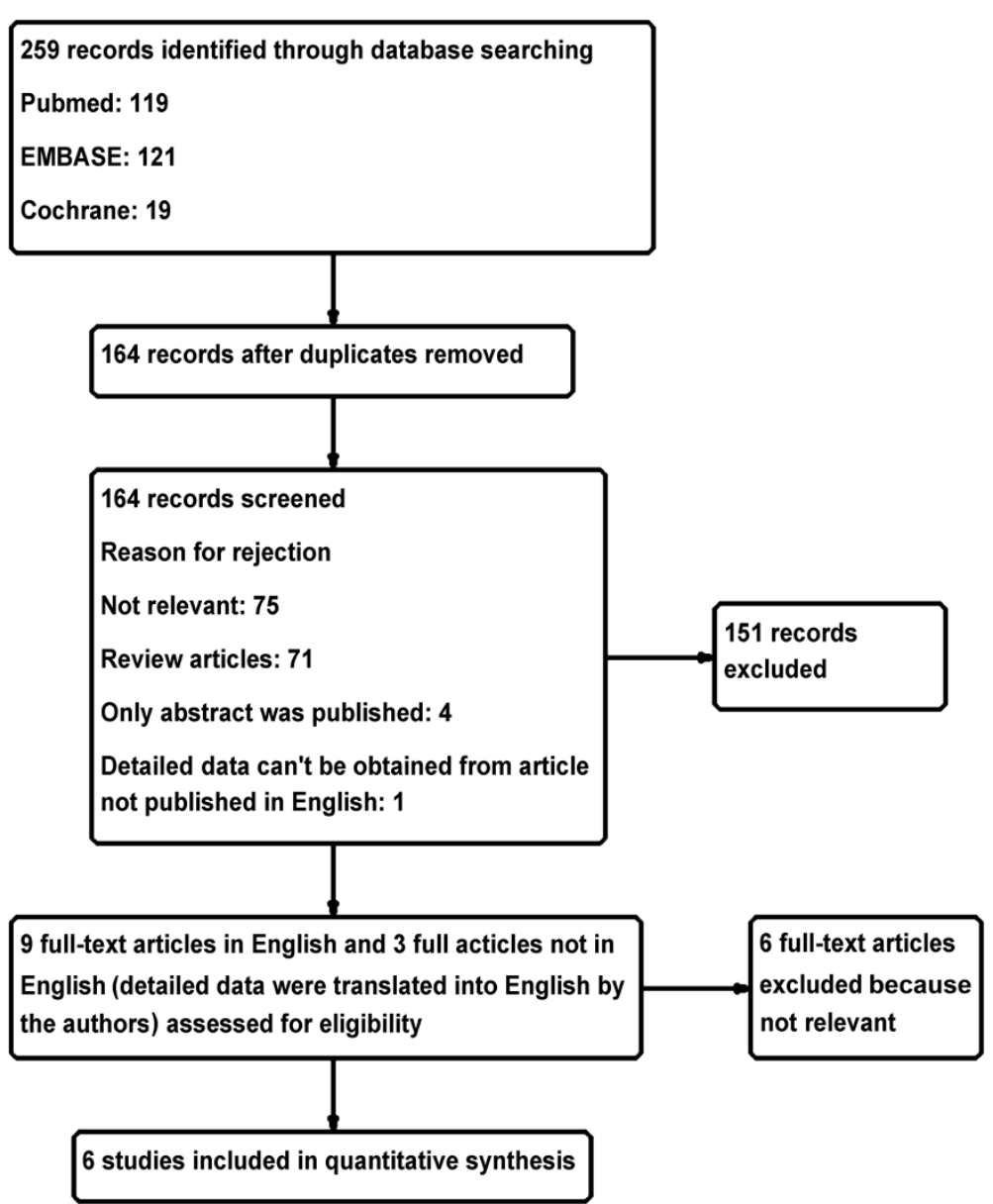

Figure 1 Flowchart illustrating the details of the search and study selection process.

Table 1. The Jadad scores of the six trials ranged from 1 to 5 . On the basis of their Jadad scores, four of the trials were of low quality $(\leq 2)$ and two were of high quality $(>2)$. An additional Microsoft Word file showing the risks of bias in more detail is in Additional file 2. Most of the trials had a high or unclear risk of selection bias, performance bias, detection bias and reporting bias. Each outcome reported in our present study is based on the results of only three to five trials; therefore, publication bias was not evaluated [40].
Types of probiotics, doses and treatment duration

In the six RCTs included in the meta-analysis, a total of 14 strains of probiotic bacteria were used (Table 2). One trial used a single strain, and the other five used a combination of probiotics containing three to six strains. Only two trials used the same mixture of probiotics: Pediococcus pentosaceus, Leuconostoc mesenteroides, L. paracasei and L. plantarum (Synbiotic 2000 Forte; Medifarm, Kågeröd, Sweden). In total, L. plantarum was used in three trials: Bifidobacterium longum, L. bulgaricus, L. paracasei, L.

Table 1 Information about the six trials

\begin{tabular}{|c|c|c|c|c|c|c|c|c|}
\hline Study & Year & Country & Blinding & Randomization & Random sequence generation & $\begin{array}{l}\text { Withdrawals } \\
\text { and dropouts }\end{array}$ & $\begin{array}{l}\text { Allocation } \\
\text { concealment }\end{array}$ & $\begin{array}{l}\text { Jadad } \\
\text { score }\end{array}$ \\
\hline Oláh et al. [26] & 2002 & Hungary & Unclear & Yes & Unclear & $0 / 0$ & Unclear & 2 \\
\hline Li et al. [25] & 2007 & China & None & Yes & Unclear & Unclear & Unclear & 1 \\
\hline Oláh et al. [27] & 2007 & Hungary & Double-blinded & Yes & Unclear & $0 / 0$ & Yes & 3 \\
\hline Besselink et al. [23] & 2008 & Netherlands & Double-blinded & Yes & $\begin{array}{l}\text { Computer-generated, } \\
\text { permuted-block sequence }\end{array}$ & $2 / 5$ & Yes & 5 \\
\hline Plaudis et al. [28] & 2012 & Latvia & Unclear & Unclear & Unclear & 0/0 & Unclear & 1 \\
\hline Cui et al. [24] & 2013 & China & None & Yes & Unclear & Unclear & Unclear & 1 \\
\hline
\end{tabular}


Table 2 Types of probiotics used in the trials

\begin{tabular}{|c|c|c|c|}
\hline Trial & Probiotics group & Control group & $\begin{array}{l}\text { Length of } \\
\text { treatment (days) }\end{array}$ \\
\hline \multirow[t]{2}{*}{ Oláh et al. [26] } & $10^{9}$ Leuconostoc plantarum 299 per serving & $10^{9}$ heat-inactivated L. plantarum 299 per serving & 7 \\
\hline & Twice daily & Twice daily & \\
\hline \multirow[t]{2}{*}{ Li et al. [25] } & $\begin{array}{l}10^{7} \text { Bifidobacterium longum, } 10^{6} \text { L. bulgaricus, and } 10^{6} \\
\text { Streptococcus thermophilus per serving (Golden Bifid) }\end{array}$ & Water & 7 \\
\hline & Thrice daily & Three times daily & \\
\hline \multirow[t]{2}{*}{ Oláh et al. [27] } & $\begin{array}{l}10^{10} \text { Pediococcus pentosaceus, } 10^{10} \mathrm{~L} \text {. mesenteroides, } 10^{10} \\
\text { L. paracasei and } 10^{10} \mathrm{~L} \text {. plantarum with bioactive fibers per } \\
\text { serving (Synbiotic } 2000 \text { Forte; Medifarm, Kågeröd, Sweden) }\end{array}$ & Bioactive fibers & 7 \\
\hline & Once daily & Once daily & \\
\hline \multirow[t]{2}{*}{ Besselink et al. [23] } & $\begin{array}{l}\text { L. acidophilus, L. casei, L. salivarius, L. lactis, B. bifidum and } \\
\text { B. lactis in a totally daily dose of } 10^{10} \text { (Ecologic } 641 ; \\
\text { Winclove Bio Industries, Amsterdam, the Netherlands) }\end{array}$ & Placebo & 28 \\
\hline & Twice daily & Twice daily & \\
\hline \multirow[t]{2}{*}{ Plaudis et al. [28] } & $\begin{array}{l}10^{10} \text { P. pentosaceus, } 10^{10} \mathrm{~L} \text {. mesenteroides, } 10^{10} \mathrm{~L} \text {. paracasei } \\
\text { and } 10^{10} \mathrm{~L} \text {. plantarum with bioactive fibers per serving } \\
\text { (Synbiotic } 2000 \text { Forte) }\end{array}$ & Bioactive fibers & Unclear \\
\hline & Twice daily & Twice daily & \\
\hline \multirow[t]{2}{*}{ Cui et al. [24] } & $\begin{array}{l}4 \times 10^{7} \text { B. longum, } 4 \times 10^{7} \text { L. bulgaricus and } 4 \times 10^{7} \\
\text { Enterococcus faecalis per serving }\end{array}$ & Water & 14 \\
\hline & Twice daily & Twice daily & \\
\hline
\end{tabular}

mesenteroides and $P$. pentosaceus were used in different combinations in two trials, and B. bifidum, B. lactis, Enterococcus faecalis, L. acidophilus, L. casei, L. lactis, L. salivarius and Streptococcus. thermophilus were used in just one trial. The lowest daily dose of probiotics was $3 \times 10^{7}$ bacteria, and the highest dose was $8 \times 10^{8}$ bacteria. The length of treatment was reported clearly in five studies, ranging from 7 to 28 days and not reported clearly in one study [28]. In three trials, the duration of treatment was 7 days [25-27], and the duration was 14 days in one study [24] and 28 days in one trial [23].

\section{Other baseline characteristics}

In the aggregate, the six included studies comprised 536 participants, and the number of participants per study ranged from 25 to 298. Among the 536 participants, 275 received EN with probiotics and 261 received probioticfree EN. The prediction variables for SAP varied between the trials: an Acute Physiology and Chronic Health Evaluation II (APACHE II) score $\geq 8$ was considered as an indicator in three studies [23-25], Glasgow (Imrie) score $\geq 3$ in four studies [23,24,26,27], C-reactive protein (CRP) level $\geq 150 \mathrm{mg} / \mathrm{L}$ in three studies [23,26,27] and extensive pancreatic necrosis in two studies $[24,25]$. In one study, SAP was predicted by APACHE II score $\geq 6$ with systemic inflammatory response syndrome and/or organ dysfunction [28].

The relevant baseline characteristics were reported in detail in three studies $[23,26,27]$, but were limited in the other three studies $[24,25,28]$. Overall, no significant differences in the baseline characteristics between the probiotics and control groups were reported. Only Besselink et al. [23] reported multiple organ failure (MOF), which occurred in $2 \%$ of the patients before randomization. The incidence of MOF before randomization, which plays a key role in the mortality associated with SAP, was 3.3\% and $0.7 \%$ in the probiotics group and control groups, respectively $(P=0.24)$ [23]. Researchers in three of the studies reported a male:female ratio of 1.80 and a mean age of 56 years $[23,26,27]$. In three studies, the investigators reported that the proportion of patients with alcoholic pancreatitis was $30.6 \%$ [23,26,27]. The Glasgow score was reported in three studies, and the APACHE II score was reported in two studies. The mean Glasgow score was 3.2 $[23,26,27]$, and the mean APACHE II score was 8.54 $[23,28]$. The plasma CRP level was reported in four studies, with an overall mean of $264.5 \mathrm{mg} / \mathrm{L}$ [23,24,26,27]. In four studies, the proportion of patients with necrotizing pancreatitis was $37 \%$ [23,26-28].

\section{Clinical outcomes}

The clinical outcomes are shown in Figure 2. In five studies comprising an aggregate total of 509 patients, the researchers reported the incidence of pancreatic infection. The difference between the probiotics and control groups was not significant in any of the five studies $(\mathrm{RR}=1.25,95 \% \mathrm{CI}=0.79$ to $1.98 ; P=0.33)$. Moreover, there was no significant heterogeneity between the studies $\left(I^{2}=43 \% ; P=0.11\right)$. 
Researchers in three studies reported total infection rates in an aggregate of 416 patients. A significantly lower total infection rate was observed in the probiotics group compared to the control group in one study (Oláh et al. [27]), and the difference between the groups was not significant in the other two studies. Overall, no significant difference was observed between the probiotics group and control group $(\mathrm{RR}=1.09,95 \% \mathrm{CI}=0.80$ to $1.48 ; P=0.57)$. Moreover, there was no significant heterogeneity between the studies $\left(I^{2}=41 \% ; P=0.18\right)$.

In four studies comprising a total of 460 patients, researchers reported the number of patients who underwent surgery. In one study, a significantly higher number of patients in the probiotics group than in the control group underwent surgery (Besselink et al. [23]). The difference between the groups was not significant in the other three studies. Overall, no significant difference was observed between the probiotics group and the control group ( $\mathrm{RR}=1.42,95 \% \mathrm{CI} 0.43$ to $3.47 ; P=0.71)$. The heterogeneity between studies was significant $\left(I^{2}=65 \%\right.$; $P=0.04)$.

In three studies comprising 369 patients, the investigators reported the duration of hospital stay. Significantly shorter hospital stays were reported in the probiotics group in two studies (Li et al. [25] and Cui et al. [24]), and no significant difference was observed in the other study. Overall, no significant difference in length of hospital stay was observed between the probiotics group and the control group $(\mathrm{MD}=2.45,95 \% \mathrm{CI}=-2.71$ to 7.60 ; $P=0.35)$. The heterogeneity between studies was significant $\left(I^{2}=72 \% ; P=0.03\right)$.

In five studies comprising 509 patients, researchers reported the mortality rates. Significantly higher mortality was observed in the probiotics group in one study (Besselink et al. [23]), and no significant difference between the probiotics and control groups was observed in the other four studies. Overall, no significant difference in length of hospital stay was observed between the probiotics and control groups $(\mathrm{RR}=0.72,95 \% \mathrm{CI}=0.42$ to $1.45 ; P=0.25)$. There was no significant heterogeneity across studies $\left(I^{2}=51 \% ; P=0.09\right)$.

We analyzed subgroups by treatment duration. Additional file 3 gives the the results in more detail. In the subgroup in which the treatment duration was within 15 days or less, a significant decrease in pancreatic infection was observed in the probiotics group compared to the control group $(\mathrm{RR}=2.94,95 \% \mathrm{CI}=1.31$ to $6.60 ; P<0.01)$. We also performed a meta-analysis of the use of probiotics in patients with critical illness with subgroup analyses conducted according to the antibiotic types and treatment durations. Additional files 4 and 5 show the results of these analyses in detail. We observed significant differences between patients taking different types of probiotics or probiotic mixtures (see Additional file 4). The subgroup in which the treatment duration was within 15 days or less showed better treatment effects than the subgroup in which the treatment duration was not limited to 15 days with regard to total infections $(\mathrm{RR}=1.49,95 \% \mathrm{CI}=1.15$ to $1.93, P<0.01$ vs. $\mathrm{RR}=1.19,95 \% \mathrm{CI}=0.98$ to $1.45, P=0.09$ ) and pneumonia $(\mathrm{RR}=1.81,95 \% \mathrm{CI}=1.27$ to $2.59, P<$ 0.01 vs. $\mathrm{RR}=1.41,95 \% \mathrm{CI}=1.09$ to $1.84, P=0.01$ ) (see Additional file 5).

\section{Discussion}

In this meta-analysis of RCTs that compared probiotics with placebo in patients with SAP, we found no evidence for probiotics' being either harmful or beneficial with regard to all important outcomes. However, significant heterogeneity was found between different trials, so the results need to be validated further.

Following the harmful effects of probiotics in SAP reported in the PROPATRIA trial [23], Sun et al. reported a meta-analysis of four RCTs with significant heterogeneity [41]. In recent years, two other RCTs have been conducted on the same subject; therefore, we conducted our present meta-analysis of all six trials with a focus on the source of the heterogeneity. The results indicate that the type and duration of treatment may contribute greatly to the heterogeneity of the results. The results of the subgroup analysis would be underpowered, with only six RCTs included in the meta-analysis. To compensate for this, we also analyzed the anti-infective effect of probiotics on the treatment of critical illness to serve as a reference.

The performance of strains differs, as different bacteria have different adherence sites and divergent immunological effects $[42,43]$. Therefore, the types of probiotics used may have led to differences in the clinical outcomes. L. plantarum 299, Synbiotic 2000 Forte and golden bifid, which were used in RCTs for the treatment of predicted SAP [25-28] have also been used in RCTs for the treatment of critical illness $[13,14,17,44-50]$. The probiotic mixture used in the Cui et al. trial contained probiotic strains similar to golden bifid [24]. These probiotics resulted in significant improvement of infection or showed a trend in that direction. However, we found no RCTs on critical illness in PubMed in which Ecologic 641 (Winclove Bio Industries, Amsterdam, the Netherlands) was used for treatment (Besselink et al. [23], PROPATRIA trial), and none of the six strains of probiotic bacteria in Ecologic 641 were used in the other five trials studied in the present meta-analysis. Further, probiotic mixtures that contained probiotic strains similar to Ecologic 641 were studied in only two of the thirteen RCTs on critical illness (Jain et al. [51] and Barraud et al. [52]), and both of these RCTs showed that probiotics had a detrimental effect on infection, although the effect was not significant (see Table 2, Figure 2 and Additional file 4). All these findings suggest that the type 
of probiotic used plays an important role in the heterogeneity between trials.

The second aspect to be considered is the dose of probiotics, as the same probiotics can have opposite effects at different doses [53]. The dose of probiotics varied greatly among the six RCTs in this meta-analysis. Even when the same probiotics were used in different trials, the doses were different. Thus, the dose may have also contributed to the heterogeneity.

The final factor to be considered is the duration of treatment, although it is still not clear whether the effects of probiotics are influenced by this variable [54]. An interesting finding was that the subgroup in which the treatment duration was within 15 days or less showed significant improvement with regard to almost all outcomes in the probiotics groups (see Additional file 3). Similarly, trials for the treatment of critical illness with treatment duration of no more than 15 days also showed higher efficacy with regard to decreased infection and reduced heterogeneity (see Additional file 5). We tentatively put forth the notion that prolonged treatment duration may lead to an overload of probiotics, which might be harmful to patients with SAP and critical illness who have intestinal barrier dysfunction. However, there is a need for evidence to confirm this hypothesis, as the results could be artefactually positive.

The PROPATRIA trial, which was the best in terms of methodological quality (Jadad score of 5), also had the highest number of participants, and the investigators used Ecologic 641 for the treatment of patients with predicted SAP, but with no beneficial effects. Some ongoing studies were abandoned after the dismal results of the PROPATRIA trial [55], and even the executors of the PROPATRIA trial thought that new randomized trials of probiotics in patients with predicted SAP were not warranted [56]. However, the dose, type and treatment duration, which have been documented to be critical factors, vary in clinical trials. Ecologic 641, which has rarely been used in other clinical trials, induced high concentrations of interleukin 10 (IL-10) and low concentrations of IL-2 compared with the other probiotics. This effect is considered to have contributed to bowel ischemia in the probiotic-treated patients in the PROPATRIA trial [57]. Therefore, the results of the PROPATRIA trial are not sufficient to draw the conclusion that probiotics are associated with adverse effects in the treatment of patients with predicted SAP.

The history of probiotic treatment of SAP is similar to that of immune formula treatment of critical illnesses. Both treatments were documented to be beneficial in animal experiments and primary clinical trials, but subsequent multicenter, prospective, randomized clinical trials showed adverse effects, which made the efficacy of the treatments questionable [58]. However, subsequent studies of immune formulations indicated that certain populations of patients did benefit from the treatment $[59,60]$. Similarly, because the trials were heterogeneous with regard to their treatment strategies and outcomes, it is still possible that patients with SAP can benefit from particular probiotics if administered at the appropriate dose and for the correct duration. Moreover, given that prophylactic antibiotics have been tried with limited or no success, the effects of probiotics with regard to their potential in decreasing necrotic tissue infection warrant further study.

In the interpretation of the results of this meta-analysis, the limited number of available trials, the methodological quality of the included trials and the heterogeneity of the included trials should be noted. Only six RCTs with relatively low methodological quality were included (that is, Jadad score $<3$ for four of the six included trials), and considerable heterogeneity was observed among these trials with regard to the effect of probiotics. The limited number of RCTs hampered the subgroup analysis conducted to understand the cause of the heterogeneity. Upon reviewing 11 major clinical practice guidelines for AP [2,29-38], we found that the use of probiotics was mentioned only in the Society of Critical Care Medicine [32] and International Association of Pancreatology and American Pancreatic Association guidelines [29]. Therefore, because of insufficient clinical data, there is clearly a need for further investigations.

\section{Conclusions}

Although the results indicate that probiotics had neither beneficial nor adverse effects, the current data are not sufficient to draw conclusions about the effects of probiotics in patients with SAP, so further studies are needed. However, the types of probiotics and treatment strategies used vary considerably across studies, so probiotic/probiotic mixtures, their appropriate dosages and treatment duration must be considered carefully before clinical trials are conducted. Moreover, considering the risks reported for certain probiotics, further clinical trials should be carefully designed to avoid any potentially harmful effects. In addition, RCTs on patients with critical illness can serve as a reference for future studies on SAP treatment.

\section{Key messages}

- The current data are not sufficient to draw conclusions about the effects of probiotics in patients with SAP because of the limited number of trials and their heterogeneity. Nonetheless, the possibility cannot be ruled out that patients with predicted SAP can benefit from particular probiotics when administered at the appropriate dose and for the correct duration. 
- The types of probiotics used and the treatment strategies employed play an important role in the heterogeneity of clinical outcomes reported in different RCTs.

- Further investigations on the effects of probiotics in patients with SAP are needed, but further clinical trials should be carefully designed to avoid any potentially harmful effects. RCTs in patients with critical illness can serve as a reference.

\section{Additional files}

Additional file 1: Systematic literature search for studies on the use of probiotics in critical illness.

Additional file 2: Risk of bias.

Additional file 3: Analysis of subgroups by treatment duration in predicted SAP.

Additional file 4: Analysis of subgroups by types of probiotics used in critical illness.

Additional file 5: Analysis of subgroups by treatment duration in critical illness.

\section{Abbreviations}

AP: Acute pancreatitis; Cl: Confidence interval; CRP: C-reactive protein; EN: Enteral nutrition; MD: Mean difference; MOF: Multiple organ failure; RCT: Randomized controlled trial; RR: Risk ratio; SAP: Severe acute pancreatitis.

\section{Competing interests}

The authors declare that they have no competing interests.

\begin{abstract}
Authors' contribution
$S G, Z Y, T L, H W$ and $C W$ were involved with study conception and design. SG, ZY and TL were involved in data acquisition. SG, ZY, HW and CW interpreted the data and results of the analyses. SG and ZY drafted the manuscript, which was critically revised for intellectual content by $\mathrm{TL}$, HW and CW. All authors read and approved the final manuscript.
\end{abstract}

\section{Authors' information}

SG and TL are pancreatic disease specialists. SG is also an intensivist at the Pancreatic Disease Institute (PDI), Union Hospital of Huazhong University of Science and Technology (HUST). ZY is a pancreatic disease specialist and the resident of the Clinician Investigator Program who is currently performing a study about fluid resuscitation in severe acute pancreatitis. HW is the deputy head of the PDI, Union Hospital of HUST. CW is the head of the PDI, the head of the Department of Surgery and the Director of the Surgical Teaching and Research Section of Union Hospital of HUST. CW is also the Vice Chairman of the Pancreatic Disease Group of the Chinese Medical Association, the Vice Chairman of the Pancreatic Cancer Committee of the Chinese Anti-Cancer Association and the Chairman of the Hubei Pancreatic Disease Association.

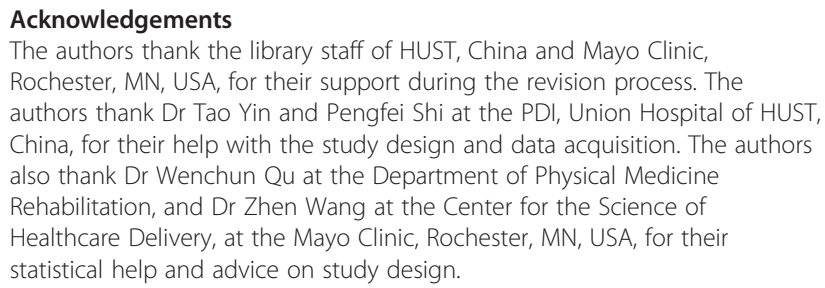
Rochester, MN, USA, for their support during the revision process. The authors thank Dr Tao Yin and Pengfei Shi at the PDI, Union Hospital of HUST, China, for their help with the study design and data acquisition. The authors also thank Dr Wenchun Qu at the Department of Physical Medicine Rehabilitation, and Dr Zhen Wang at the Center for the Science of Healthcare Delivery, at the Mayo Clinic, Rochester, MN, USA, for their statistical help and advice on study design.

Received: 18 November 2013 Accepted: 4 March 2014

Published: 31 March 2014

\section{References}

1. Peery AF, Dellon ES, Lund J, Crockett SD, McGowan CE, Bulsiewicz WJ, Gangarosa LM, Thiny MT, Stizenberg K, Morgan DR, Ringel Y, Kim HP, Dibonaventura MD, Carroll CF, Allen JK, Cook SF, Sandler RS, Kappelman MD, Shaheen NJ: Burden of gastrointestinal disease in the United States: 2012 update. Gastroenterology 2012, 143:1179-1187. e3.

2. UK Working Party on Acute Pancreatitis: UK guidelines for the management of acute pancreatitis. Gut 2005, 54:iii1-iii9.

3. Beger HG, Rau B, Isenmann R: Natural history of necrotizing pancreatitis. Pancreatology 2003, 3:93-101.

4. Bradley EL 3rd, Dexter ND: Management of severe acute pancreatitis: a surgical odyssey. Ann Surg 2010, 251:6-17.

5. Dervenis C, Smailis D, Hatzitheoklitos E: Bacterial translocation and its prevention in acute pancreatitis. J Hepatobiliary Pancreat Surg 2003, 10:415-418.

6. Van Felius ID, Akkermans LM, Bosscha K, Verheem A, Harmsen W, Visser MR, Gooszen HG: Interdigestive small bowel motility and duodenal bacterial overgrowth in experimental acute pancreatitis. Neurogastroenterol Motil 2003, 15:267-276.

7. van Minnen LP, Nieuwenhuijs VB, de Bruijn MT, Verheem A, Visser MR, van Dijk JE, Akkermans LM, Gooszen HG: Effects of subtotal colectomy on bacterial translocation during experimental acute pancreatitis. Pancreas 2006, 32:110-114.

8. van Minnen LP, Timmerman HM, Lutgendorff F, Verheem A, Harmsen W, Konstantinov SR, Smidt H, Visser MR, Rijkers GT, Gooszen HG, Akkermans LM: Modification of intestinal flora with multispecies probiotics reduces bacterial translocation and improves clinical course in a rat model of acute pancreatitis. Surgery 2007, 141:470-480.

9. Akyol S, Mas MR, Comert B, Ateskan Ü, Yasar M, Aydogan H, Deveci S, Akay C, Mas N, Yener N, Kocar $\mathrm{IH}$ : The effect of antibiotic and probiotic combination therapy on secondary pancreatic infections and oxidative stress parameters in experimental acute necrotizing pancreatitis. Pancreas 2003, 26:363-367.

10. Muftuoglu MAT, Isikgor S, Tosun S, Saglam A: Effects of probiotics on the severity of experimental acute pancreatitis. Eur J Clin Nutr 2006, 60:464-468.

11. Karen M, Yuksel O, Akyürek N, Ofluoğlu E, Çağlar $K$, Şahin T, Paşaoğlu H, Memiş L, Akyürek N, Bostanci H: Probiotic agent Saccharomyces boulardii reduces the incidence of lung injury in acute necrotizing pancreatitis induced rats. J Surg Res 2010, 160:139-144.

12. Shimizu K, Ogura H, Goto M, Asahara T, Nomoto K, Morotomi M, Matsushima A, Tasaki O, Fujita K, Hosotsubo H, Kuwagata Y, Tanaka H, Shimazu T, Sugimoto H: Synbiotics decrease the incidence of septic complications in patients with severe SIRS: a preliminary report. Dig Dis Sci 2009, 54:1071-1078.

13. Giamarellos-Bourboulis EJ, Bengmark S, Kanellakopoulou K, Kotzampassi K: Pro- and synbiotics to control inflammation and infection in patients with multiple injuries. J Trauma 2009, 67:815-821.

14. Knight DJ, Gardiner D, Banks A, Snape SE, Weston VC, Bengmark S, Girling $\mathrm{KJ}$ : Effect of synbiotic therapy on the incidence of ventilator associated pneumonia in critically ill patients: a randomised, double-blind, placebocontrolled trial. Intensive Care Med 2009, 35:854-861.

15. Frohmader TJ, Chaboyer WP, Robertson IK, Gowardman J: Decrease in frequency of liquid stool in enterally fed critically ill patients given the multispecies probiotic VSL\#3: a pilot trial. Am J Crit Care 2010, 19:e1-e11.

16. Alberda C, Gramlich L, Meddings J, Field C, McCargar L, Kutsogiannis D, Fedorak R, Madsen K: Effects of probiotic therapy in critically ill patients: a randomized, double-blind, placebo-controlled trial. Am J Clin Nutr 2007, 85:816-823.

17. Kotzampassi K, Giamarellos-Bourboulis EJ, Voudouris A, Kazamias P, Eleftheriadis E: Benefits of a synbiotic formula (Synbiotic 2000Forte) in critically III trauma patients: early results of a randomized controlled trial. World J Surg 2006, 30:1848-1855.

18. Barraud D, Bollaert PE, Gibot S: Impact of the administration of probiotics on mortality in critically ill adult patients: a meta-analysis of randomized controlled trials. Chest 2013, 143:646-655.

19. Möndel M, Schroeder BO, Zimmermann K, Huber H, Nuding S, Beisner J, Fellermann K, Stange EF, Wehkamp J: Probiotic E. coli treatment mediates antimicrobial human $\beta$-defensin synthesis and fecal excretion in humans. Mucosal Immunol 2009, 2:166-172.

20. Duquesne S, Petit $V$, Peduzzi J, Rebuffat $S$ : Structural and functional diversity of microcins, gene-encoded antibacterial peptides from enterobacteria. J Mol Microbiol Biotechnol 2007, 13:200-209. 
21. Rea MC, Clayton E, O'Connor PM, Shanahan F, Kiely B, Ross RP, Hill C: Antimicrobial activity of lacticin 3147 against clinical Clostridium difficile strains. J Med Microbiol 2007, 56:940-946.

22. Kabeerdoss J, Devi RS, Mary RR, Prabhavathi D, Vidya R, Mechenro J, Mahendri NV, Pugazhendhi S, Ramakrishna BS: Effect of yoghurt containing Bifidobacterium lactis $\mathrm{Bb} 12$ on faecal excretion of secretory immunoglobulin $A$ and human $\beta$-defensin 2 in healthy adult volunteers. Nutr J 2011, 10:138.

23. Besselink MG, van Santvoort HC, Buskens E, Boermeester MA, van Goor $H$, Timmerman HM, Nieuwenhuijs VB, Bollen TL, van Ramshorst B, Witteman BJ, Rosman C, Ploeg RJ, Brink MA, Schaapherder AF, Dejong CH, Wahab PJ, van Laarhoven CJ, van der Harst E, van Eijck CH, Cuesta MA, Akkermans LM, Gooszen HG, the Dutch Acute Pancreatitis Study Group: Probiotic prophylaxis in predicted severe acute pancreatitis: a randomised, double-blind, placebo-controlled trial. Lancet 2008, 371:651-659.

24. Cui $L H$, Wang $X H$, Peng $L H, Y u L$, Yang YS: The effects of early enteral nutrition with addition of probiotics on the prognosis of patients suffering from severe acute pancreatitis [in Chinese]. Zhonghua Wei Zhong Bing Ji Jiu Yi Xue 2013, 25:224-228.

25. Li Y: Adjuvant therapy for probiotics in patients with severe acute pancreatitis: an analysis of 14 cases [in Chinese]. Shijie Huaren Xiaohua Zazhi 2007, 15:302-304.

26. Oláh A, Belágyi T, Issekutz A, Gamal ME, Bengmark S: Randomized clinical trial of specific Lactobacillus and fibre supplement to early enteral nutrition in patients with acute pancreatitis. Br J Surg 2002, 89:1103-1107.

27. Oláh A, Belágyi T, Pótó L, Romics L Jr, Bengmark S: Synbiotic control of inflammation and infection in severe acute pancreatitis: a prospective, randomized, double blind study. Hepatogastroenterology 2007, 54:590-594.

28. Plaudis H, Pupelis G, Zeiza K, Boka V: Early low volume oral synbiotic/ prebiotic supplemented enteral stimulation of the gut in patients with severe acute pancreatitis: a prospective feasibility study. Acta Chir Belg 2012, 112:131-138.

29. Working Group IAP/APA Acute Pancreatitis Guidelines: IAP/APA evidencebased guidelines for the management of acute pancreatitis. Pancreatology 2013, 13:e1-e15.

30. Toouli J, Brooke-Smith M, Bassi C, Carr-Locke D, Telford J, Freeny P, Imrie C, Tandon R: Guidelines for the management of acute pancreatitis. J Gastroenterol Hepatol 2002, 17:S15-S39.

31. Meier R, Beglinger C, Layer P, Gullo L, Keim V, Laugier R, Friess $H$, Schweitzer $M$, MacFie J, ESPEN Consensus Group: ESPEN guidelines on nutrition in acute pancreatitis. Clin Nutr 2002, 21:173-183.

32. Nathens AB, Curtis JR, Beale RJ, Cook DJ, Moreno RP, Romand JA, Skerrett SJ, Stapleton RD, Ware LB, Waldmann CS: Management of the critically ill patient with severe acute pancreatitis. Crit Care Med 2004, 32:2524-2536.

33. Banks PA, Freeman ML: Practice guidelines in acute pancreatitis. Am J Gastroenterol 2006, 101:2379-2400.

34. Takeda K, Takada T, Kawarada Y, Hirata K, Mayumi T, Yoshida M, Sekimoto M, Hirota M, Kimura Y, Isaji S, Koizumi M, Otsuki M, Matsuno S: JPN Guidelines for the management of acute pancreatitis: medical management of acute pancreatitis. J Hepatobiliary Pancreat Surg 2006, 13:42-47.

35. Otsuki M, Hirota M, Arata S, Koizumi M, Kawa S, Kamisawa T, Takeda K, Mayumi T, Kitagawa M, Ito T, Inui K, Shimosegawa T, Tanaka S, Kataoka K, Saisho H, Okazaki K, Kuroda Y, Sawabu N, Takeyama Y, the Research Committee of Intractable Diseases of the Pancreas: Consensus of primary care in acute pancreatitis in Japan. World J Gastroentero/ 2006, 12:3314-3323.

36. American Gastroenterological Association Institute (AGA) on "Management of Acute Pancreatitis" Clinical Practice and Economics Committee; AGA Institute Governing Board: AGA Institute Medical Position Statement on Acute Pancreatitis. Gastroenterology 2007, 132:2019-2021.

37. Pezzilli R, Uomo G, Zerbi A, Gabbrielli A, Frulloni L, De Rai P, Delle Fave G, Di Carlo V, Italian Association for the Study of the Pancreas and Prolnf AISP (Computerized Project on Acute Pancreatitis) Study Group: Diagnosis and treatment of acute pancreatitis: the position statement of the Italian Association for the Study of the Pancreas. Dig Liver Dis 2008, 40:803-808.

38. Mirtallo JM, Forbes A, McClave SA, Jensen GL, Waitzberg DL, Davies AR, International Consensus Guideline Committee Pancreatitis Task Force: International consensus guidelines for nutrition therapy in pancreatitis. JPEN J Parenter Enteral Nutr 2012, 36:284-291.

39. Jadad AR, Moore RA, Carroll D, Jenkinson C, Reynolds DJ, Gavaghan DJ, McQuay HJ: Assessing the quality of reports of randomized clinical trials: Is blinding necessary? Control Clin Trials 1996, 17:1-12.
40. Ioannidis JP, Trikalinos TA: The appropriateness of asymmetry tests for publication bias in meta-analyses: a large survey. CMAJ 2007, 176:1091-1096.

41. Sun S, Yang K, He X, Tian J, Ma B, Jiang L: Probiotics in patients with severe acute pancreatitis: a meta-analysis. Langenbecks Arch Surg 2009, 394:171-177.

42. Macho Fernandez E, Valenti V, Rockel C, Hermann C, Pot B, Boneca IG, Grangette C: Anti-inflammatory capacity of selected lactobacilli in experimental colitis is driven by NOD2-mediated recognition of a specific peptidoglycan-derived muropeptide. Gut 2011, 60:1050-1059.

43. Meijerink M, van Hemert S, Taverne N, Wels M, de Vos P, Bron PA, Savelkoul $H F$, van Bilsen J, Kleerebezem M, Wells JM: Identification of genetic loci in Lactobacillus plantarum that modulate the immune response of dendritic cells using comparative genome hybridization. PLoS One 2010, 5:e10632.

44. Klarin B, Molin G, Jeppsson B, Larsson A: Use of the probiotic Lactobacillus plantarum 299 to reduce pathogenic bacteria in the oropharynx of intubated patients: a randomised controlled open pilot study. Crit Care 2008, 12:R136

45. McNaught CE, Woodcock NP, Anderson ADG, MacFie J: A prospective randomised trial of probiotics in critically ill patients. Clin Nutr 2005, 24:211-219.

46. Oudhuis GJ, Bergmans DC, Dormans T, Zwaveling JH, Kessels A, Prins MH, Stobberingh EE, Verbon A: Probiotics versus antibiotic decontamination of the digestive tract: infection and mortality. Intensive Care Med 2011, 37:110-117.

47. Rayes N, Hansen S, Seehofer D, Müller AR, Serke S, Bengmark S, Neuhaus P: Early enteral supply of fiber and lactobacilli versus conventional nutrition: a controlled trial in patients with major abdominal surgery. Nutrition 2002, 18:609-615.

48. Rayes N, Seehofer D, Theruvath T, Schiller RA, Langrehr JM, Jonas S, Bengmark S, Neuhaus P: Supply of pre- and probiotics reduces bacterial infection rates after liver transplantation-a randomized, double-blind trial. Am J Transplant 2005, 5:125-130.

49. Spindler-Vesel A, Bengmark S, Vovk I, Cerovic O, Kompan L: Synbiotics, prebiotics, glutamine, or peptide in early enteral nutrition: a randomized study in trauma patients. JPEN J Parenter Enteral Nutr 2007, 31:119-126.

50. Tan M, Zhu JC, Du J, Zhang LM, Yin HH: Effects of probiotics on serum levels of Th1/Th2 cytokine and clinical outcomes in severe traumatic brain-injured patients: a prospective randomized pilot study. Crit Care 2011, 15:R290.

51. Jain PK, McNaught CE, Anderson ADG, MacFie J, Mitchell CJ: Influence of synbiotic containing Lactobacillus acidophilus La5, Bifidobacterium lactis Bb 12, Streptococcus thermophilus, Lactobacillus bulgaricus and oligofructose on gut barrier function and sepsis in critically ill patients: a randomised controlled trial. Clin Nutr 2004, 23:467-475.

52. Barraud D, Blard C, Hein F, Marçon O, Cravoisy A, Nace L, Alla F, Bollaert PE, Gibot S: Probiotics in the critically ill patient: a double blind, randomized, placebo-controlled trial. Intensive Care Med 2010, 36:1540-1547.

53. Wen K, Li G, Bui T, Liu F, Li Y, Kocher J, Lin L, Yang X, Yuan L: High dose and low dose Lactobacillus acidophilus exerted differential immune modulating effects on $\mathrm{T}$ cell immune responses induced by an oral human rotavirus vaccine in gnotobiotic pigs. Vaccine 2012, 30:1198-1207.

54. Boyanova L, Mitov I: Coadministration of probiotics with antibiotics: Why, when and for how long? Expert Rev Anti Infect Ther 2012, 10:407-409.

55. Sharma B, Srivastava S, Singh N, Sachdev V, Kapur S, Saraya A: Role of probiotics on gut permeability and endotoxemia in patients with acute pancreatitis: a double-blind randomized controlled trial. J Clin Gastroenterol 2011, 45:442-448.

56. Besselink MGH, van Santvoort HC, van der Heijden GJMG, Buskens E, Gooszen HG: New randomized trial of probiotics in pancreatitis needed? Caution advised. Langenbecks Arch Surg 2009, 394:191-194.

57. Capurso G, Marignani M, Piciucchi M, Merola E, Delle Fave G: Probiotics and severe acute pancreatitis [Addendum]. J Clin Gastroenterol 2008, 42:S152-S153.

58. Bower RH, Cerra FB, Bershadsky B, Licari JJ, Hoyt DB, Jensen GL, Van Buren CT, Rothkopf MM, Daly JM, Adelsberg BR: Early enteral administration of a formula (Impact) supplemented with arginine, nucleotides, and fish oil in intensive care unit patients: results of a multicenter, prospective, randomized, clinical trial. Crit Care Med 1995, 23:436-449.

59. Montejo JC, Zarazaga A, López-Martínez J, Urrútia G, Roqué M, Blesa AL, Celaya S, Conejero R, Galbán C, García de Lorenzo A, Grau T, Mesejo A, Ortiz-Leyba C, 
Planas M, Ordóñez J, Jiménez FJ; for the Nutritional and Metabolic Working Group of the Spanish Society of Intensive Care Medicine and Coronary Units (SEMICYUC), Spain: Immunonutrition in the intensive care unit: a systematic review and consensus statement. Clin Nutr 2003, 22:221-233.

60. Wilhelm SM, Kale-Pradhan PB: Combination of arginine and $\omega-3$ fatty acids enteral nutrition in critically ill and surgical patients: a meta-analysis. Expert Rev Clin Pharmacol 2010, 3:459-469.

doi:10.1186/cc13809

Cite this article as: Gou et al:: Use of probiotics in the treatment of severe acute pancreatitis: a systematic review and meta-analysis of randomized controlled trials. Critical Care 2014 18:R57.

\section{Submit your next manuscript to BioMed Central and take full advantage of:}

- Convenient online submission

- Thorough peer review

- No space constraints or color figure charges

- Immediate publication on acceptance

- Inclusion in PubMed, CAS, Scopus and Google Scholar

- Research which is freely available for redistribution 